\title{
Caracterização dos acidentes de trabalho notificados de 2009 a 2018 em Franca-SP
}

\author{
Characterization of work accidents notified from 2009 to 2018 in Franca-SP
}

\author{
Caracterización de accidentes de trabajo notificados de 2009 a 2018 en Franca-SP \\ Felipe Mauri do Prado ${ }^{1 *}$, Elton Batista de Souza Filho ${ }^{1}$, Tarcila de Almeida Santos Machado \\ Mazer².
}

\section{RESUMO}

Objetivo: Analisar e caracterizar os acidentes de trabalho notificados no Centro de Referência em Saúde do Trabalhador (CEREST) de Franca-SP. Métodos: Trata-se de um estudo descritivo, retrospectivo e transversal, com abordagem quantitativa de 63.438 casos de acidentes de trabalho notificados no período de 2009 a 2018 no CEREST de Franca-SP. O referido CEREST atende Franca e mais 21 municípios. Acerca da caracterização dos acidentes, as variáveis utilizadas foram: tipo, agente causador, gravidade da lesão, parte do corpo acometida, setor produtivo, gênero e idade. A partir dos resultados foi realizada análise crítica. Resultados: A maioria dos acidentes registrados no estudo foram típicos, ocasionados por agentes mecânicos, classificados como leves e que acometiam as mãos. O setor de serviços e indústrias são locais importantes desses acidentes. Em relação ao perfil das vítimas, encontrou-se que homens de 22 a 39 anos estão mais suscetíveis aos acidentes. Variações durante a série histórica estudada foram encontradas principalmente no que tange ao setor produtivo. Conclusão: Uma adequada avaliação situacional dos acidentes ocupacionais da região de Franca pode embasar uma posterior implementação de estratégias preventivas.

Palavras-chave: Acidentes de trabalho, Saúde ocupacional, Notificação de acidentes de trabalho.

\begin{abstract}
Objective: To analyze and characterize occupational accidents notified at the Reference Center for Occupational Health (CEREST) in Franca-SP. Methods: This is a descriptive, retrospective and crosssectional study, with a quantitative approach of 63,438 cases of occupational accidents reported in the period from 2009 to 2018 at CEREST in Franca-SP. The referred CEREST serves Franca and 21 other municipalities. Regarding the characterization of accidents, the variables used were: reason, causative agent, severity of the injury, body part affected, productive sector, gender and age. Based on the results, a critical analysis was carried out and they were compared with the state and national situation of accidents at work. Results: Most of the accidents recorded in the study were typical accidents, caused by mechanical agents, classified as mild and affecting the hands. The service sector and industries are important locations for these accidents. Regarding the profile of the victims, it was found that men aged 22 to 39 years are more susceptible to accidents. Variations during the historical series studied were found mainly with respect to the productive sector. Conclusion: An adequate situational assessment of occupational accidents in the Franca region can support a subsequent implementation of preventive strategies.
\end{abstract}

Key words: Accidents, Occupational, Occupational health, Occupational accidents registry.

\section{RESUMEN}

Objetivo: Analizar y caracterizar los accidentes laborales notificados en el Centro de Referencia para la Salud Ocupacional (CEREST) en Franca-SP. Métodos: Este es un estudio descriptivo, retrospectivo y transversal, con un enfoque cuantitativo de 63,438 casos de accidentes laborales reportados en el período de 2009 a 2018 en CEREST de Franca-SP. El referido CEREST atiende a Franca y otras 21 ciudades. En cuanto a la caracterización de los accidentes, las variables utilizadas son: razón, agente causal, gravedad de la lesión, parte del cuerpo afectada, sector productivo, género y edad. Con base en los resultados, se realizó un análisis crítico. Resultados: La mayoría de los accidentes registrados en el estudio fueron típicos, causados por

1Universidade de Franca (UNIFRAN). Franca - SP. *E-mail: felipemaurip@gmail.com 
agentes mecánicos, clasificados como leves y que afectan las manos. El sector de servicios y las industrias son sitios importantes em los cuales estos acidentes occurren. Con respecto al perfil de las víctimas, se encontró que los hombres de 22 a 39 años son más susceptibles a los accidentes. Las variaciones durante la serie histórica estudiada se encontraron principalmente con respecto al sector productivo. Conclusión: Una evaluación situacional adecuada de los accidentes laborales en la región de Franca puede respaldar una implementación posterior de estrategias preventivas.

Palabras clave: Accidentes de trabajo, Salud laboral, Notificación de accidentes del trabajo.

\section{INTRODUÇÃO}

No Brasil, os acidentes de trabalho e as políticas ao redor desta questão são de competência do Sistema Único de Saúde (SUS) e de alguns órgãos tais como o Instituto Nacional do Seguro Social (INSS), o Ministério da Saúde, o Ministério da Economia, o Ministério Público do Trabalho e a Justiça do Trabalho. Tais órgãos trabalham em conjunto visando a melhoria das condições e da saúde dos trabalhadores, seja através da elaboração de leis, da elaboração de políticas públicas de saúde ou do tratamento e reabilitação dos trabalhadores. O artigo 19 da lei $n^{\circ} 8213$, de 24 de julho de 1991, após reformulação dada pela redação da Lei Complementar ํㅜ 150, de 2015, define que:

"acidente do trabalho é o que ocorre pelo exercício do trabalho a serviço de empresa ou de empregador doméstico ou pelo exercício do trabalho dos segurados referidos no inciso VII do artigo 11 desta Lei, provocando lesão corporal ou perturbação funcional que cause a morte ou a perda ou redução, permanente ou temporária, da capacidade para o trabalho" (BRASIL, 1991).

Dessa forma, percebe-se que a preocupação com a segurança do trabalho é relativamente recente na história brasileira. A notificação dos acidentes de trabalho é importante para o funcionamento das políticas públicas e para a prevenção dos acidentes. No entanto, é notória a ocorrência de subnotificações, principalmente em países subdesenvolvidos, como os latino-americanos, onde estima-se que as notificações girem em torno de $7,6 \%$ (ALMEIDA PCA, BARBOSA-BRANCO A, 2011).

Acidente de trabalho é aquele que ocorre pelo exercício do trabalho a serviço da empresa, provocando lesão corporal ou perturbação funcional que cause morte, ou perda, ou redução, permanente ou temporária, da capacidade para o trabalho. Equiparam-se ao acidente de trabalho, para os fins desta lei: a doença profissional ou do trabalho, assim entendida a inerente ou peculiar a determinado ramo de atividade e constante de relação organizada pelo Ministério da Previdência e Assistência Social (MPAS). O acidente que, ligado ao trabalho, embora não tenha sido a causa única, haja contribuindo diretamente para a morte, ou perda, ou redução da capacidade para o trabalho. $O$ acidente sofrido pelo empregado ainda que fora do local e horário de trabalho (BRASIL, 1976).

A publicação da Medida Provisária no 905, de 11 de novembro de 2019, havia instituído o Contrato de Trabalho Verde e Amarelo e alterado a legislação trabalhista (BRASIL, 2019). Dentre estas alterações, havia sido revogado o art.21, inciso IV, letra "d", da Lei $n^{\circ} 8.213 / 91$, que equiparava o acidente de trajeto sofrido pelo empregado ao acidente de trabalho típico. No entanto, esta Medida Provisória foi revogada pela Medida Provisória no 955, de 20 de abril de 2020 (BRASIL, 2020). Assim, no período em que a Medida Provisóaria no 905 ficou vigente - de 12 de novembro de 2019 a 20 de abril de 2020 - o acidente de trajeto deixou de ser notificado à Previdência Social através da Comunicação de Acidente de Trabalho (CAT), sendo que neste período, estes trabalhadores que se acidentaram, perderam garantias trabalhistas, entre elas a estabilidade de um ano no trabalho após o retorno do afastamento do trabalho pelo acidente de trajeto. Importante ressaltar que as notificações compulsórias do SINAN se referem somente aos acidentes de trabalho graves, dentre os quais enquadram-se os acidentes de trabalho em menores de 18 anos, os mutilantes ou fatais (MINISTÉRIO DA SAÚDE, 2006). Quanto à notificação do ponto de vista previdenciário, temos a obrigatoriedade do preenchimento da Comunicação de Acidente de Trabalho (CAT), documento emitido para o reconhecimento de acidente em um dos três grupos de classificação anteriormente citados. 
A emissão da CAT e notificação do mesmo à Previdência é obrigatória por lei, sendo necessária notificação até um dia útil após ocorrência do acidente, mesmo nos casos em que não há afastamento do trabalho. Em caso de morte, a notificação se faz necessária imediatamente, segundo o artigo 336 do decreto número 3.048 de seis de maio de 1999, ainda vigente (BRASIL, 1999).

Com relação ao SUS, foi criado outro instrumento de notificação, semelhante à CAT da Previdência: o Relatório de Atendimento ao Acidentado do Trabalho (RAAT). Este instrumento é encaminhado ao Centro de Referência em Saúde do Trabalhador (CEREST), responsável pelo monitoramento da saúde do trabalhador no SUS. As notificações direcionadas ao SINAN são realizadas pela Vigilância Epidemiológica do município. Este estudo busca analisar e caracterizar os acidentes de trabalho e traçar o perfil das vítimas dos mesmos, ocorridos na região atendida pelo CEREST de Franca, São Paulo, notificados no período de 2009 a 2018. Entende-se a importância da temática para a saúde pública, bem como a necessidade de discutir sobre 0 tema com vistas à prevenção e promoção de um ambiente de labor mais seguro para o trabalhador.

\section{MÉTODOS}

Trata-se de um estudo descritivo, retrospectivo e transversal, com abordagem quantitativa de 63.438 casos de acidentes de trabalho notificados no período de 2009 a 2018, no Centro de Referência em Saúde do Trabalhador (CEREST) de Franca-SP. Os dados foram disponibilizados pelo CEREST após autorização do diretor da instituição, a qual possui parceria com a Universidade de Franca. Tais números foram extraídos do Sistema Integrado de Saúde (SIGS), o qual é alimentado por dados dos Relatórios de Atendimento ao Acidentado do Trabalho (RAAT) pela rede do SUS de Franca e da região, composta por unidades básicas de saúde, pronto socorro, unidades de pronto atendimento e hospitais. O referido CEREST atende Franca e mais 21 municípios: Aramina, Buritizal, Cristais Paulista, Guará, Igarapava, Ipuã, Itirapuã, Ituverava, Jeriquara, Miguelópolis, Morro Agudo, Nuporanga, Orlândia, Patrocínio Paulista, Pedregulho, Restinga, Ribeirão Corrente, Rifaina, Sales Oliveira, São Joaquim da Barra, São José da Bela Vista. De acordo com o Censo Demográfico de 2010 (IBGE, 2011), a população dessa região é composta de 649.807 habitantes, sendo 340.320 pessoas economicamente ativas.

O estudo realizou caracterização do perfil das vítimas de acidente de trabalho na região. Acerca da caracterização dos acidentes, as variáveis utilizadas foram: tipo, agente causador, gravidade da lesão, parte do corpo acometida e setor produtivo. As variáveis utilizadas para o perfil das vítimas foram: gênero e idade. Em relação ao setor produtivo, o CEREST informou que os dados de 2018 , que são contabilizados manualmente, não estão cadastrados ainda. Por este motivo, a análise dos acidentes quanto ao setor produtivo foi apresentada em tabela separada das demais variáveis. Com os resultados realizou-se análise crítica e comparativa com a situação estadual e nacional em relação aos acidentes de trabalho. Os dados referentes a São Paulo e Brasil foram extraídos dos anuários estatísticos disponibilizados pela Previdência Social, que avaliam os acidentes notificados por CAT. Trata-se de um estudo cujos dados foram obtidos de banco de dados, já tabulados, agregados, sem a menor possibilidade de acesso a informações pessoais pelos pesquisadores, logo não se fez necessária aprovação prévia do Comitê de Ética em Pesquisa, conforme consta no artigo $1^{\circ}$, inciso $\mathrm{V}$, da resolução número 510 , de sete de abril de 2016 , do Ministério da Saúde (BRASIL, 2016).

\section{RESULTADOS E DISCUSSÃO}

O CEREST de Franca-SP registrou 63.438 casos de acidentes ocupacionais no período entre 2009 e 2018 , por meio dos RAAT do SUS. Uma média de 6.343,80 casos por ano, com o menor valor encontrado em 2009 e o maior em 2011, com respectivamente 3.406 e 8.315 acidentes relatados (Tabelas 1 e 2). Vale ressaltar que o número total de casos entre as tabelas possui uma pequena divergência devido a erro na extração dos dados do SIGS e no preenchimento incompleto nesse sistema; essa disparidade, no entanto, não é suficiente para alterar contundentemente a análise dos dados. 


\section{Revista Eletrônica Acervo Saúde / Electronic Journal Collection Health | ISSN 2178-2091}

Tabela 1 - Caracterização dos acidentes de trabalho notificados e registrados no Centro de Referência em Saúde do Trabalhador (CEREST) de Franca-SP, no período de 2009 a 2013, de acordo com as variáveis: Tipo de acidente, Agente causador, Gravidade da lesão e Parte do corpo acometida.

\begin{tabular}{|c|c|c|c|c|c|c|c|c|c|c|}
\hline \multirow[b]{2}{*}{ Variável } & \multicolumn{2}{|c|}{2009} & \multicolumn{2}{|c|}{2010} & \multicolumn{2}{|c|}{2011} & \multicolumn{2}{|c|}{2012} & \multicolumn{2}{|c|}{2013} \\
\hline & $\mathbf{n}$ & $\%$ & $\mathbf{n}$ & $\%$ & $\mathbf{n}$ & $\%$ & $\mathbf{n}$ & $\%$ & $\mathbf{n}$ & $\%$ \\
\hline \multicolumn{11}{|l|}{ Tipo de acidente } \\
\hline Acidente de trabalho típico & 2.829 & $83,06 \%$ & 5.519 & $79,20 \%$ & 6.652 & $80,00 \%$ & 6.455 & $79,61 \%$ & 5.409 & 2.829 \\
\hline Acidente de trajeto & 517 & $15,18 \%$ & 1.417 & $20,34 \%$ & 1.634 & $19,65 \%$ & 1.638 & $20,20 \%$ & 1.555 & 517 \\
\hline Não especificado & 21 & $0,62 \%$ & 5 & $0,07 \%$ & 5 & $0,06 \%$ & 3 & $0,04 \%$ & 5 & 21 \\
\hline Doença ocupacional & 26 & $0,76 \%$ & 23 & $0,33 \%$ & 12 & $0,14 \%$ & 10 & $0,12 \%$ & 5 & 26 \\
\hline Não informado & 13 & $0,38 \%$ & 4 & $0,06 \%$ & 12 & $0,14 \%$ & 2 & $0,02 \%$ & 13 & 13 \\
\hline \multicolumn{11}{|l|}{ Agente causador } \\
\hline Biológico & 47 & $1,38 \%$ & 104 & $1,49 \%$ & 98 & $1,18 \%$ & 65 & $0,80 \%$ & 58 & $0,83 \%$ \\
\hline Físico & 137 & $4,02 \%$ & 303 & $4,35 \%$ & 286 & $3,44 \%$ & 177 & $2,18 \%$ & 184 & $2,63 \%$ \\
\hline Mecânico/Acid. & 3.054 & $89,67 \%$ & 6.228 & $89,38 \%$ & 7.570 & $91,04 \%$ & 7.462 & $92,03 \%$ & 6.389 & $91,44 \%$ \\
\hline Não encontrado & 0 & $0,00 \%$ & 9 & $0,13 \%$ & 0 & $0,00 \%$ & 0 & $0,00 \%$ & 0 & $0,00 \%$ \\
\hline Químico & 71 & $2,08 \%$ & 180 & $2,58 \%$ & 188 & $2,26 \%$ & 192 & $2,37 \%$ & 141 & $2,02 \%$ \\
\hline Ergonômico & 97 & $2,85 \%$ & 144 & $2,07 \%$ & 173 & $2,08 \%$ & 212 & $2,61 \%$ & 215 & $3,08 \%$ \\
\hline \multicolumn{11}{|l|}{ Gravidade da lesão } \\
\hline Leve & 2.719 & $79,83 \%$ & 5.755 & $82,59 \%$ & 6.769 & $81,41 \%$ & 6.745 & $83,19 \%$ & 5.641 & $80,74 \%$ \\
\hline Moderada & 418 & $12,27 \%$ & 929 & $13,33 \%$ & 1.158 & $13,93 \%$ & 1.095 & $13,51 \%$ & 1.162 & $16,63 \%$ \\
\hline Grave & 132 & $3,88 \%$ & 248 & $3,56 \%$ & 347 & $4,17 \%$ & 196 & $2,42 \%$ & 95 & $1,36 \%$ \\
\hline Fatal & 6 & $0,18 \%$ & 9 & $0,13 \%$ & 14 & $0,17 \%$ & 13 & $0,16 \%$ & 8 & $0,11 \%$ \\
\hline Não informada & 131 & $3,85 \%$ & 27 & $0,39 \%$ & 27 & $0,32 \%$ & 59 & $0,73 \%$ & 81 & $1,16 \%$ \\
\hline
\end{tabular}


Revista Eletrônica Acervo Saúde / Electronic Journal Collection Health | ISSN 2178-2091

\begin{tabular}{|c|c|c|c|c|c|c|c|c|c|c|}
\hline \multicolumn{11}{|c|}{ Parte do corpo acometida } \\
\hline Cabeça & 170 & $4,99 \%$ & 393 & $5,64 \%$ & 515 & $6,19 \%$ & 435 & $5,37 \%$ & 442 & $6,33 \%$ \\
\hline Pescoço & 8 & $0,23 \%$ & 21 & $0,30 \%$ & 32 & $0,38 \%$ & 28 & $0,35 \%$ & 29 & $0,42 \%$ \\
\hline Olho & 298 & $8,75 \%$ & 605 & $8,68 \%$ & 667 & $8,02 \%$ & 652 & $8,04 \%$ & 446 & $6,38 \%$ \\
\hline Coluna & 230 & $6,75 \%$ & 482 & $6,92 \%$ & 465 & $5,59 \%$ & 556 & $6,86 \%$ & 530 & $7,59 \%$ \\
\hline Tórax & 61 & $1,79 \%$ & 178 & $2,55 \%$ & 202 & $2,43 \%$ & 236 & $2,91 \%$ & 177 & $2,53 \%$ \\
\hline Mão & 1.385 & $40,66 \%$ & 2.510 & $36,02 \%$ & 2.878 & $34,61 \%$ & 2.770 & $34,16 \%$ & 2.257 & $32,30 \%$ \\
\hline Pé & 320 & $9,40 \%$ & 592 & $8,50 \%$ & 739 & $8,89 \%$ & 715 & $8,82 \%$ & 619 & $8,86 \%$ \\
\hline Abdome & 10 & $0,29 \%$ & 38 & $0,55 \%$ & 37 & $0,44 \%$ & 44 & $0,54 \%$ & 28 & $0,40 \%$ \\
\hline Vias respiratórias & 4 & $0,12 \%$ & 13 & $0,19 \%$ & 14 & $0,17 \%$ & 17 & $0,21 \%$ & 7 & $0,10 \%$ \\
\hline Membro superior & 357 & $10,48 \%$ & 924 & $13,26 \%$ & 1.154 & $13,88 \%$ & 1.034 & $12,75 \%$ & 1.017 & $14,56 \%$ \\
\hline Membro inferior & 314 & $9,22 \%$ & 989 & $14,19 \%$ & 1.199 & $14,42 \%$ & 1.150 & $14,18 \%$ & 1.019 & $14,58 \%$ \\
\hline Múltiplas & 51 & $1,50 \%$ & 180 & $2,58 \%$ & 361 & $4,34 \%$ & 387 & $4,77 \%$ & 310 & $4,44 \%$ \\
\hline Outros não informados & 198 & $5,81 \%$ & 43 & $0,62 \%$ & 52 & $0,63 \%$ & 84 & $1,04 \%$ & 106 & $1,52 \%$ \\
\hline Total & 3.406 & $100 \%$ & 6.968 & $100 \%$ & 8.315 & $100 \%$ & 8.108 & $100 \%$ & 6.987 & $100 \%$ \\
\hline
\end{tabular}

Fonte: Souza-Filho EB, et al., 2020. Dados extraídos do CEREST de Franca, São Paulo. 


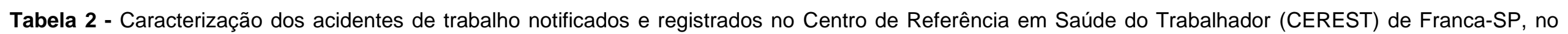
período de 2014 a 2018, de acordo com as variáveis: Tipo de acidente, Agente causador, Gravidade da lesão e Parte do corpo acometida (N=63.438).

\begin{tabular}{|c|c|c|c|c|c|c|c|c|c|c|c|c|}
\hline \multirow[b]{2}{*}{ Variável } & \multicolumn{2}{|c|}{2014} & \multicolumn{2}{|c|}{2015} & \multicolumn{2}{|c|}{2016} & \multicolumn{2}{|c|}{2017} & \multicolumn{2}{|c|}{2018} & \multicolumn{2}{|c|}{$\begin{array}{c}\text { Total } \\
2009 \text { a } 2018\end{array}$} \\
\hline & $\mathbf{n}$ & $\%$ & $n$ & $\%$ & $\mathbf{n}$ & $\%$ & $\mathbf{n}$ & $\%$ & $\mathbf{n}$ & $\%$ & $n$ & $\%$ \\
\hline \multicolumn{13}{|l|}{ Tipo de acidente } \\
\hline Típico & 4.857 & $77,19 \%$ & 3.977 & $74,31 \%$ & 3.892 & $71,73 \%$ & 4.650 & $74,0 \%$ & 4.541 & $72,11 \%$ & 48.781 & $76,90 \%$ \\
\hline De trajeto & 1.410 & $22,41 \%$ & 1.347 & $25,17 \%$ & 1.485 & $27,37 \%$ & 1.558 & $24,8 \%$ & 1.590 & $25,25 \%$ & 14.151 & $22,31 \%$ \\
\hline Não especificado & 9 & $0,14 \%$ & 10 & $0,19 \%$ & 12 & $0,22 \%$ & 40 & $0,6 \%$ & 145 & $2,30 \%$ & 255 & $0,40 \%$ \\
\hline Doença ocupacional & 6 & $0,10 \%$ & 2 & $0,04 \%$ & 4 & $0,07 \%$ & 9 & $0,1 \%$ & 4 & $0,06 \%$ & 101 & $0,16 \%$ \\
\hline Não informado & 10 & $0,16 \%$ & 16 & $0,30 \%$ & 33 & $0,61 \%$ & 30 & $0,5 \%$ & 17 & $0,27 \%$ & 150 & $0,24 \%$ \\
\hline \multicolumn{13}{|l|}{ Agente causador } \\
\hline Biológico & 74 & $1,18 \%$ & 49 & $0,92 \%$ & 64 & $1,18 \%$ & 349 & $5,55 \%$ & 144 & $2,29 \%$ & 1.052 & $1,66 \%$ \\
\hline Físico & 179 & $2,84 \%$ & 167 & $3,12 \%$ & 121 & $2,23 \%$ & 372 & $5,92 \%$ & 152 & $2,41 \%$ & 2.078 & $3,28 \%$ \\
\hline $\begin{array}{l}\text { Mecânico/ } \\
\text { Acid. }\end{array}$ & 5.653 & $89,84 \%$ & 4.908 & $91,70 \%$ & 5.046 & $93,00 \%$ & 5.219 & $83,01 \%$ & 4.110 & $65,27 \%$ & 55.639 & $87,71 \%$ \\
\hline Não encontrado & 0 & $0,00 \%$ & 0 & $0,00 \%$ & 0 & $0,00 \%$ & 41 & $0,65 \%$ & 1.607 & $25,52 \%$ & 1.657 & $2,61 \%$ \\
\hline Químico & 142 & $2,26 \%$ & 108 & $2,02 \%$ & 88 & $1,62 \%$ & 96 & $1,53 \%$ & 99 & $1,57 \%$ & 1.305 & $2,06 \%$ \\
\hline Ergonômico & 244 & $3,88 \%$ & 120 & $2,24 \%$ & 107 & $1,97 \%$ & 210 & $3,34 \%$ & 185 & $2,94 \%$ & 1.707 & $2,69 \%$ \\
\hline \multicolumn{13}{|l|}{ Gravidade da lesão } \\
\hline Leve & 4.894 & $77,78 \%$ & 4.223 & $78,91 \%$ & 4.307 & $79,38 \%$ & 4.844 & $77,05 \%$ & 4.920 & $78,13 \%$ & 50.817 & $80,10 \%$ \\
\hline Moderada & 1.225 & $19,47 \%$ & 987 & $18,44 \%$ & 994 & $18,32 \%$ & 1.281 & $20,38 \%$ & 1.199 & $19,04 \%$ & 10.448 & $16,47 \%$ \\
\hline Grave & 113 & $1,80 \%$ & 94 & $1,76 \%$ & 85 & $1,57 \%$ & 107 & $1,70 \%$ & 160 & $2,54 \%$ & 1.577 & $2,49 \%$ \\
\hline Fatal & 11 & $0,17 \%$ & 21 & $0,39 \%$ & 10 & $0,18 \%$ & 15 & $0,24 \%$ & 9 & $0,14 \%$ & 116 & $0,18 \%$ \\
\hline Não informada & 49 & $0,78 \%$ & 27 & $0,50 \%$ & 30 & $0,55 \%$ & 40 & $0,64 \%$ & 9 & $0,14 \%$ & 480 & $0,76 \%$ \\
\hline
\end{tabular}


Revista Eletrônica Acervo Saúde / Electronic Journal Collection Health | ISSN 2178-2091

\begin{tabular}{|c|c|c|c|c|c|c|c|c|c|c|c|c|}
\hline \multicolumn{13}{|c|}{ Parte do corpo acometida } \\
\hline Cabeça & 345 & $5,48 \%$ & 337 & $6,30 \%$ & 312 & $5,75 \%$ & 368 & $5,85 \%$ & 388 & $6,16 \%$ & 3.705 & $5,84 \%$ \\
\hline Pescoço & 24 & $0,38 \%$ & 19 & $0,36 \%$ & 21 & $0,39 \%$ & 22 & $0,35 \%$ & 30 & $0,48 \%$ & 234 & 0,37\% \\
\hline Olho & 361 & $5,74 \%$ & 297 & $5,55 \%$ & 265 & $4,88 \%$ & 318 & $5,06 \%$ & 320 & $5,08 \%$ & 4.229 & $6,67 \%$ \\
\hline Coluna & 517 & $8,22 \%$ & 306 & $5,72 \%$ & 324 & $5,97 \%$ & 352 & $5,60 \%$ & 321 & $5,10 \%$ & 4.083 & $6,44 \%$ \\
\hline Tórax & 172 & $2,73 \%$ & 113 & $2,11 \%$ & 139 & $2,56 \%$ & 159 & $2,53 \%$ & 152 & $2,41 \%$ & 1.589 & $2,50 \%$ \\
\hline Mão & 2.035 & $32,34 \%$ & 1.672 & $31,24 \%$ & 1.676 & $30,89 \%$ & 1.917 & $30,49 \%$ & 1.990 & $31,60 \%$ & 21.090 & $33,25 \%$ \\
\hline Pé & 544 & $8,65 \%$ & 550 & $10,28 \%$ & 495 & $9,12 \%$ & 537 & $8,54 \%$ & 575 & $9,13 \%$ & 5.686 & $8,96 \%$ \\
\hline Abdome & 26 & $0,41 \%$ & 26 & $0,49 \%$ & 31 & $0,57 \%$ & 25 & $0,40 \%$ & 24 & $0,38 \%$ & 289 & $0,46 \%$ \\
\hline Vias respiratórias & 6 & $0,10 \%$ & 5 & $0,09 \%$ & 7 & $0,13 \%$ & 21 & $0,33 \%$ & 16 & $0,25 \%$ & 110 & $0,17 \%$ \\
\hline Membro superior & 951 & $15,11 \%$ & 769 & $14,37 \%$ & 804 & $14,82 \%$ & 1.026 & $16,32 \%$ & 938 & $14,90 \%$ & 8.974 & $14,15 \%$ \\
\hline Membro inferior & 966 & $15,35 \%$ & 881 & $16,46 \%$ & 959 & $17,67 \%$ & 1.061 & $16,88 \%$ & 1.071 & $17,01 \%$ & 9.609 & $15,15 \%$ \\
\hline Múltiplas & 284 & $4,51 \%$ & 334 & $6,24 \%$ & 348 & $6,41 \%$ & 427 & $6,79 \%$ & 449 & $7,13 \%$ & 3.131 & $4,94 \%$ \\
\hline $\begin{array}{l}\text { Outros não } \\
\text { informados }\end{array}$ & 61 & $0,97 \%$ & 43 & $0,80 \%$ & 45 & $0,83 \%$ & 54 & $0,86 \%$ & 23 & $0,37 \%$ & 709 & $1,12 \%$ \\
\hline Total & 6.292 & $100 \%$ & 5.352 & $100 \%$ & 5.426 & $100 \%$ & 6.287 & $100 \%$ & 6.297 & $100 \%$ & 63.438 & $100 \%$ \\
\hline
\end{tabular}

Fonte: Souza-Filho EB, et al., 2020. Dados extraídos do CEREST de Franca, São Paulo. 
A emissão da RAAT centraliza as ações que devem ser instituídas pelo CEREST, que presta atendimento especializado aos trabalhadores e que tem o trabalho facilitado pela construção de um perfil epidemiológico a partir destes registros. Enquanto isso, a Comunicação de Acidente de Trabalho é o instrumento utilizado no âmbito Federal, pela Previdência Social, com o objetivo de normatizar os gastos do Tesouro Nacional, de acordo com os acidentes, visando o pagamento de direitos garantidos pela legislação: auxílio-doença acidentário, auxílio-acidente e aposentadoria por invalidez, de acordo com a gravidade do acidente de trabalho ocorrido.

De acordo com a Previdência Social, no ano de 2017, foram identificados 549,4 mil acidentes ocupacionais e 313.891 auxílios acidentes ativos, cuja despesa anual totalizou $R \$ 4.135 .908$, além dos gastos com pensões acidentárias e aposentadorias decorrentes de processos acidentários (MINISTÉRIO DA FAZENDA, 2017). Estes números corroboram, portanto, para a necessidade de empenho das entidades governamentais em medidas preventivas e assistenciais. Assim sendo, a visão holística destas esferas evidencia uma descentralização necessária para uma correta e assertiva administração de recursos e esforços para o amparo do trabalhador acidentado.

\section{Tipo de Acidente}

Os acidentes de trabalho podem ser classificados quanto ao tipo em: acidente de trabalho típico, acidente de trajeto ou doença ocupacional. No período analisado, $76,90 \%(n=48.781)$ dos acidentes eram típicos, $22,31 \%(n=14.151)$ de trajeto e $0,16 \%(n=101)$ doença ocupacional. Uma pequena parcela $(0,63 \%, n=255)$ dos acidentes sem especificação, ou seja, em 255 notificações não houve a adequada notificação sobre qual o tipo do acidente, ainda que estes se encontrem dentro da formalidade, uma vez que houve registro de acidente (Tabelas 1 e 2).

O aparente número pouco expressivo de doenças ocupacionais notificadas deve fomentar um olhar um pouco mais crítico na análise contextual. Doenças do trabalho tendem a ser mais subnotificadas do que acidentes gerais, e não necessariamente ocorrerem em frequência tão baixa quanto a verificada no presente estudo. A subnotificação se dá, por muitas das vezes, devido às dificuldades que se apresentam para o estabelecimento do nexo causal (PINTO JM, 2017).

No estado de São Paulo, entre 2009 e 2017, ocorreram 2.070.978 acidentes ocupacionais. Observa-se, também, uma predominância dos acidentes típicos, que corresponde a $64,80 \%$ do total. Os acidentes de trajeto representam $17,59 \%(n=364.363)$ e as doenças ocupacionais $2,27 \%$ do total. Os acidentes sem preenchimento da CAT ocorreram em 15,32\% das vezes (MINISTÉRIO DA ECONOMIA, 2020)

Quanto aos dados nacionais no período em questão, observa-se, também, uma predominância dos acidentes típicos em $60,07 \%$ dos casos, sendo 22,22\% deles sem CAT (MINISTÉRIO DA ECONOMIA, 2020), embora haja obrigatoriedade da geração deste documento por lei (PINTO JM, 2017). Mesmo que houvesse preenchimento em todas as situações determinadas, ou seja, para todos os trabalhadores que estão vinculados ao Regime Geral da Previdência Social (RGPS), ainda teríamos um sub-registro de acidentes do trabalho. Isso porque o RGPS não abrange funcionários públicos civis e militares estatutários, trabalhadores previdenciários autônomos, empregados domésticos e proprietários (CORDEIRO R, et al., 2005).

A nível nacional, os acidentes de trajeto representam $15,41 \%$ e as doenças ocupacionais $2,2 \%$ do total (MINISTÉRIO DA ECONOMIA, 2020). Observa-se, pois, que nos números francanos há uma maior proporção de acidentes típicos e de trajeto e um menor número de doença ocupacional, ao se comparar com os índices estadual e brasileiro.

\section{Agente Causador}

Quanto ao agente causador do acidente, nota-se uma predominância significativa dos mecânicos, que corresponde a $87,7 \%(n=55.639)$ dos casos em todo o período. O segundo mais prevalente é o agente físico, o qual corresponde a apenas $3,27 \%(n=2.078)$ do total (Tabela 2). Este perfil sugere a importante influência da atividade industrial no município. A Norma Regulamentadora o 9 do Ministério do Trabalho tem por objetivo a implementação do Programa de Prevenção de Riscos Ambientais pelos empregadores. Consiste em estratégias e controle de riscos ambientes que existem ou possam existir no ambiente de trabalho, sendo 
elencados como tais os agentes físicos, químicos e biológicos (MINISTÉRIO DO TRABALHO, 1978). Os agentes mecânicos não estão incluídos nesta norma, indicando a incipiente regulamentação sobre a proteção do trabalhador neste quesito. Este fato pode ser considerado como um dos múltiplos fatores que colocam agentes mecânicos como o mais comum, em detrimento aos outros agentes.

\section{Gravidade da Lesão}

Quanto à gravidade da lesão, nota-se o predomínio das lesões leves em comparação às demais, correspondendo a $80,10 \%(n=50.817)$ dos casos. Houve um aumento significativo de lesionados leves, de 2009 a 2012, com um pico no ano de 2011, e após com diminuição dos casos e manutenção, sem variações bruscas.

Nota-se que não houve esclarecimento sobre esse quesito em $480(0,75 \%)$ casos do total de 63.438 registrados na evolução entre 2009 e 2018 sobre a gravidade da lesão. Embora essa porcentagem possa parecer, em um primeiro momento, irrisória, temos não somente uma interferência na criação de políticas que amparam o trabalhador nos casos de subnotificação, como também uma interferência direta em índices sensíveis ao país, entre eles os coeficientes de mortalidade, a taxa de letalidade e os riscos potenciais de acidentes graves em determinado ramo de atividade ou empresa, quando não temos o registro correto de acidente fatais.

De acordo com a literatura nacional, as subnotificações podem ser influenciadas de acordo com o grau da lesão e o porte da empresa do trabalhador. Há, proporcionalmente aos números totais de registro, um maior número de acidentes graves em microempresas do que em empresas de grande porte. Tal ponto é explicado pela menor notificação de acidentes leves por empresas de pequeno porte, que mostram uma tendência a notificação apenas de casos mais graves, o que, em parte, também explica o porquê dos períodos de afastamento de microempresas apresentaram média maior do que grandes empresas (ALMEIDA FSS, 2011).

\section{Parte do Corpo Acometida}

É imperioso destacar que o maior índice de acidentes atinge a projeção das mãos dos trabalhadores, correspondendo a $33,25 \%(n=21.090)$ dos casos no período (Tabelas 1 e 2). Este fato pode refletir um importante número de trabalho manual da região, uma vez que as principais atividades econômicas se baseiam nos serviços e no setor industrial, especialmente a indústria calçadista, com inúmeros casos de acidente de trabalho acometendo as mãos.

Em segundo lugar aparece como foco das lesões os membros inferiores, com 15,15\% ( $n=9.609)$ dos casos e em seguida, os membros superiores com $14,15 \%$ ( $n=8.974)$ dos casos. Em penúltimo e último lugar aparecem, respectivamente, as lesões em pescoço, com 0,37\% ( $n=234)$ dos casos, e o acometimento das vias respiratórias, que representam apenas $0,17 \%(n=110)$ dos casos notificados no período. $O$ índice não informado corresponde a 1,12\% $(n=709)$ dos casos (Tabela 2).

No Brasil, em 2017, as três lesões mais incidentes foram "ferimento do punho e da mão", "fratura ao nível do punho ou da mão" e "luxação, entorse e distensão das articulações e dos ligamentos ao nível do tornozelo e do pé", de acordo com o Código Internacional de Doença (MINISTÉRIO DA ECONOMIA, 2020).

De fato, essas lesões são corriqueiras. Barbosa RI, et al. (2013), em estudo sobre o perfil dos pacientes com lesões no membro superior atendidos no Hospital das Clínicas da Faculdade de Medicina de Ribeirão Preto, evidenciou que os tendões mais acometidos do membro superior foram os da topografia das mãos, em especial, dos músculos flexores do punho e dos dedos. Além disso, mostrou, também, que as principais causas das lesões de punho e mão são, em ordem decrescente, acidentes com motocicletas, com máquinas, ferimentos com vidro, queda da própria altura, trauma direto e queda de altura (BARBOSA RI, et al., 2013).

\section{Setor Produtivo}

Observa-se que $26,66 \%$ ( $n=14.656)$ e $22,94 \%$ ( $n=12.612)$ dos acidentes ocupacionais, no que tange ao setor produtivo aconteceu, durante todo o período analisado, no ramo dos serviços e da indústria calçadista, respectivamente (Tabela 3 e 4). Isso pode ser reflexo do quanto esses setores econômicos são preponderantes no município de Franca, fato este corroborado pelos dados do IBGE, que demonstram a 
predominância dos setores de serviço e indústria no produto interno bruto da cidade de Franca na última década (IBGE, 2017). Tal observação indica quais áreas necessitam de mais esforços de prevenção de traumas no trabalho.

$\mathrm{Na}$ comparação com os dados nacionais, a secretaria da Previdência apontou para as atividades hospitalares como causadora da maior parte dos acidentes de trabalho no ano de 2017 no Brasil (MINISTÉRIO DA FAZENDA, 2017). Essa disparidade advém, entre outros fatores, do alto grau de industrialização que o município de Franca dispõe desde o período do Estado Novo, que possibilitaram a importação em massa de maquinários industriais para região que, historicamente, já possuía quantidade significativa de curtumes por ser grande produtora de couro (FRANCO-BENATTI DM, 2011).

No início da série do presente estudo, a construção civil configurava como a terceira maior responsável pelos acidentes notificados, estando em 2009 com 14,11\% $(n=480)$ dos registros daquele ano. A indústria calçadista estava em primeiro lugar com $35,01 \%(n=1.191)$ e o setor de serviços, em segundo, com $15,78 \%$ ( $n=537$ ) (Tabela 3). Em 2017, último ano com dado sobre esta variável, a construção civil representava apenas $5,33 \%(n=231)$ dos acidentes notificados (Tabela 4). Esta dinâmica na ordem do setor produtivo durante a série histórica estudada reflete um momento ímpar da Economia Mundial quando a construção civil foi um dos setores que mais sofreu com a crise econômica da última década. De acordo com Bastos PLM (2017), houve uma diminuição dos acidentes de trabalho no setor da construção civil, em Portugal, caindo de 47.024 em 2008 para 27.309 em 2014. Ou ainda, pode sugerir uma significativa melhoria nas ações preventivas neste setor. O CEREST de Franca não forneceu os dados referentes ao ano de 2018, no que se refere ao setor produtivo. A explicação oferecida foi que os dados são extraídos das RAAT manualmente, e ainda não foi possível contabilizar os acidentes de 2018 sob esta variável. No entanto, os autores acreditam que esta lacuna não interfere na apreciação das demais informações e não invalida o estudo.

Tabela 3 - Caracterização dos acidentes de trabalho notificados e registrados no Centro de Referência em Saúde do Trabalhador (CEREST) de Franca-SP, no período de 2009 a 2013, segundo a variável: Setor produtivo ( $\mathrm{N}=54.983)$.

\begin{tabular}{|c|c|c|c|c|c|c|c|c|c|c|}
\hline \multirow[b]{2}{*}{ Variável } & \multicolumn{2}{|c|}{2009} & \multicolumn{2}{|c|}{2010} & \multicolumn{2}{|c|}{2011} & \multicolumn{2}{|c|}{2012} & \multicolumn{2}{|c|}{2013} \\
\hline & $\mathbf{n}$ & $\%$ & $\mathbf{n}$ & $\%$ & $\mathbf{n}$ & $\%$ & $\mathbf{n}$ & $\%$ & $\mathbf{n}$ & $\%$ \\
\hline \multicolumn{11}{|l|}{ Setor produtivo } \\
\hline Agropecuário & 118 & $3,47 \%$ & 413 & $6,03 \%$ & 599 & $7,21 \%$ & 520 & $6,42 \%$ & 335 & $4,80 \%$ \\
\hline Alimentício & 224 & $6,58 \%$ & 297 & $4,33 \%$ & 484 & $5,83 \%$ & 569 & $7,02 \%$ & 490 & $7,02 \%$ \\
\hline Calçados & 1.191 & $35,01 \%$ & 1.770 & $25,83 \%$ & 2.009 & $24,19 \%$ & 1.904 & $23,50 \%$ & 1.714 & $24,57 \%$ \\
\hline Comércio & 398 & $11,70 \%$ & 596 & $8,70 \%$ & 451 & $5,43 \%$ & 439 & $5,42 \%$ & 470 & $6,74 \%$ \\
\hline Construção civil & 480 & $14,11 \%$ & 858 & $12,52 \%$ & 1.005 & $12,10 \%$ & 959 & $11,84 \%$ & 847 & $12,14 \%$ \\
\hline Curtume & 58 & $1,70 \%$ & 273 & $3,98 \%$ & 258 & $3,11 \%$ & 184 & $2,27 \%$ & 211 & $3,02 \%$ \\
\hline Ind. borracha & 0 & $0,00 \%$ & 181 & $2,64 \%$ & 152 & $1,83 \%$ & 99 & $1,22 \%$ & 75 & $1,07 \%$ \\
\hline \multirow{2}{*}{$\begin{array}{l}\text { Limpeza urbana } \\
\text { Mecânica/ } \\
\text { metalúrgico }\end{array}$} & 88 & $2,59 \%$ & 130 & $1,90 \%$ & 169 & $2,03 \%$ & 162 & $2,00 \%$ & 122 & $1,75 \%$ \\
\hline & 213 & $6,26 \%$ & 480 & $7,00 \%$ & 679 & $8,18 \%$ & 687 & $8,48 \%$ & 552 & $7,91 \%$ \\
\hline Saúde & 74 & $2,18 \%$ & 195 & $2,85 \%$ & 152 & $1,83 \%$ & 138 & $1,70 \%$ & 121 & $1,73 \%$ \\
\hline Serviços & 537 & $15,78 \%$ & 1.316 & $19,20 \%$ & 1.919 & $23,11 \%$ & 2.159 & $26,65 \%$ & 1.896 & $27,18 \%$ \\
\hline Têxtil & 0 & $0,00 \%$ & 19 & $0,28 \%$ & 31 & $0,37 \%$ & 30 & $0,37 \%$ & 7 & $0,10 \%$ \\
\hline Usina & 0 & $0,00 \%$ & 262 & $3,82 \%$ & 397 & $4,78 \%$ & 252 & $3,11 \%$ & 137 & $1,96 \%$ \\
\hline Não especificado & 21 & $0,62 \%$ & 53 & $0,77 \%$ & 0 & $0,00 \%$ & 0 & $0,00 \%$ & 0 & $0,00 \%$ \\
\hline Ind.química & 0 & $0,00 \%$ & 10 & $0,15 \%$ & 0 & $0,00 \%$ & 0 & $0,00 \%$ & 0 & $0,00 \%$ \\
\hline Total & 3.402 & $100 \%$ & 6.853 & $100 \%$ & 8.305 & $100 \%$ & 8.102 & $100 \%$ & 6.977 & $100 \%$ \\
\hline
\end{tabular}

Fonte: Souza-Filho EB, et al., 2020. Dados extraídos do CEREST de Franca, São Paulo. 
Tabela 4 - Caracterização dos acidentes de trabalho notificados e registrados no Centro de Referência em Saúde do Trabalhador (CEREST) de Franca-SP, no período de 2014 a 2018, segundo a variável: Setor produtivo $(\mathrm{N}=54.983)$.

\begin{tabular}{|c|c|c|c|c|c|c|c|c|c|c|c|c|}
\hline \multirow[b]{2}{*}{ Variável } & \multicolumn{2}{|c|}{2014} & \multicolumn{2}{|c|}{2015} & \multicolumn{2}{|c|}{2016} & \multicolumn{2}{|c|}{2017} & \multicolumn{2}{|c|}{2018} & \multicolumn{2}{|c|}{$\begin{array}{c}\text { Total } \\
2009 \text { a } 2018\end{array}$} \\
\hline & $\mathbf{n}$ & $\%$ & $\mathbf{n}$ & $\%$ & $\mathrm{n}$ & $\%$ & $\mathbf{n}$ & $\%$ & $\mathbf{n}$ & $\%$ & $\mathbf{n}$ & $\%$ \\
\hline \multicolumn{13}{|c|}{ Setor produtivo } \\
\hline Agropecuário & 285 & $4,53 \%$ & 250 & $4,68 \%$ & 252 & $4,68 \%$ & 110 & $2,54 \%$ & - & - & 2.882 & $5,24 \%$ \\
\hline Alimentício & 478 & $7,61 \%$ & 395 & $7,40 \%$ & 395 & $7,34 \%$ & 486 & $11,20 \%$ & - & - & 3.818 & $6,94 \%$ \\
\hline Calçados & 1.375 & $21,88 \%$ & 966 & $18,10 \%$ & 997 & $18,52 \%$ & 686 & $15,81 \%$ & - & - & 12.612 & $22,94 \%$ \\
\hline Comércio & 470 & $7,48 \%$ & 527 & $9,87 \%$ & 486 & $9,03 \%$ & 252 & $5,81 \%$ & - & - & 4.089 & $7,44 \%$ \\
\hline $\begin{array}{l}\text { Construção } \\
\text { civil }\end{array}$ & 777 & $12,36 \%$ & 571 & $10,70 \%$ & 506 & $9,40 \%$ & 231 & $5,33 \%$ & - & - & 6.234 & $11,34 \%$ \\
\hline Curtume & 181 & $2,88 \%$ & 125 & $2,34 \%$ & 114 & $2,12 \%$ & 96 & $2,21 \%$ & - & - & 1.500 & $2,73 \%$ \\
\hline Ind. borracha & 64 & $1,02 \%$ & 46 & $0,86 \%$ & 37 & $0,69 \%$ & 57 & $1,31 \%$ & - & - & 711 & $1,29 \%$ \\
\hline $\begin{array}{l}\text { Limpeza } \\
\text { urbana }\end{array}$ & 102 & $1,62 \%$ & 117 & $2,19 \%$ & 111 & $2,06 \%$ & 77 & $1,78 \%$ & - & - & 1.078 & $1,96 \%$ \\
\hline $\begin{array}{l}\text { Mecânica/ } \\
\text { metalúrgico }\end{array}$ & 508 & $8,08 \%$ & 395 & $7,40 \%$ & 398 & $7,39 \%$ & 75 & $1,73 \%$ & - & - & 3.987 & $7,25 \%$ \\
\hline Saúde & 151 & $2,40 \%$ & 172 & $3,22 \%$ & 187 & $3,47 \%$ & 242 & $5,58 \%$ & - & - & 1.432 & $2,60 \%$ \\
\hline Serviços & 1.739 & $27,67 \%$ & 1.525 & $28,57 \%$ & 1.711 & $31,79 \%$ & 1.854 & $42,74 \%$ & - & - & 14.656 & $26,66 \%$ \\
\hline Têxtil & 14 & $0,22 \%$ & 6 & $0,11 \%$ & 0 & $0,00 \%$ & 8 & $0,18 \%$ & - & - & 115 & $0,21 \%$ \\
\hline Usina & 141 & $2,24 \%$ & 243 & $4,55 \%$ & 189 & $3,51 \%$ & 4 & $0,09 \%$ & - & - & 1.625 & $2,96 \%$ \\
\hline $\begin{array}{l}\text { Não } \\
\text { especificado }\end{array}$ & 0 & $0,00 \%$ & 0 & $0,00 \%$ & 0 & $0,00 \%$ & 134 & $3,09 \%$ & - & - & 208 & $0,38 \%$ \\
\hline Ind.química & 0 & $0,00 \%$ & 0 & $0,00 \%$ & 0 & $0,00 \%$ & 26 & $0,60 \%$ & - & - & 36 & $0,07 \%$ \\
\hline Total & 6.285 & $100 \%$ & 5.338 & $100 \%$ & 5.383 & $100 \%$ & 4.338 & $100 \%$ & - & - & 54.983 & $100 \%$ \\
\hline
\end{tabular}

Fonte: Souza-Filho EB, et al., 2020, dados extraídos do CEREST de Franca, São Paulo.

\section{Gênero}

Identifica-se uma predominância significativa das vítimas do sexo masculino, em relação ao feminino, correspondendo a, respectivamente, $72,25 \%(n=45.636)$ e $27,72 \%(n=17.508)$ do total de 63.163 registradas sob esta variável. Esta proporção se manteve, sem grandes alterações, durante toda série estudada (Tabelas 5 e 6). Estes dados estão bem próximos aos encontrados por Machado TAS (2007), que ao implantar e, posteriormente, analisar sistema de captação de acidentes do trabalho em Hospital Escola da Faculdade de Medicina de Botucatu, SP, encontrou o predomínio de $73,8 \%$ de homens e $24 \%$ de mulheres $(2,2 \%$ não possuíam esta informação). A análise mais comumente inferida a partir dessa discrepância é a de que homens se acidentam mais por corresponderem à maior fatia daqueles responsáveis por trabalhos manuais e de risco. São eles que desenvolvem serviços pesados, que exigem força física, com maior risco de se acidentarem.

No entanto, devemos nos lembrar que as mulheres representam porcentagem já superior a $40 \%$ da mãode-obra no mercado internacional, e ainda assim com número de acidentes significativamente menor, fato que pode ser explicado, dentre outros fatores, por serem também a proporção mais prejudicada pelo trabalho informal, que não entra nas estatísticas oficiais dos acidentes de trabalho, devido ao não preenchimento da Comunicação de Acidente de Trabalho (SOUZA TV, 2016). 
O número total de RAAT registrados em relação à variável gênero foi de 63.163 (Tabela 6), uma diferença de 275 acidentes em relação as outras variáveis, como motivo do acidente (Tabela 2). Esta divergência pode ser explicada pela dificuldade de contabilizar os dados, provocando vieses. O CEREST recebe os RAAT que são preenchidos nas unidades de saúde da região atendida, e então, os dados são extraídos manualmente para um sistema integrado de saúde. As falhas podem ocorrer no preenchimento dos RAAT, bem como na extração dos dados. Esse fato indica a necessidade de atualização dos métodos de notificação e registro dos acidentes ocupacionais, a fim de se evitar perda de dados, formação de vieses e desperdício de recursos (tempo e funcionários).

Tabela 5 - Perfil das vítimas de acidentes ocupacionais notificados e registrados no Centro de Referência em Saúde do Trabalhador (CEREST) de Franca-SP, no período de 2009 a 2013, conforme as variáveis Gênero $(\mathrm{N}=63.163)$ e Idade $(\mathrm{N}=63.112)$.

\begin{tabular}{|c|c|c|c|c|c|c|c|c|c|c|}
\hline \multirow[b]{2}{*}{ Variável } & \multicolumn{2}{|c|}{2009} & \multicolumn{2}{|c|}{2010} & \multicolumn{2}{|c|}{2011} & \multicolumn{2}{|c|}{2012} & \multicolumn{2}{|c|}{2013} \\
\hline & $\mathbf{n}$ & $\%$ & $\mathbf{n}$ & $\%$ & $\mathbf{n}$ & $\%$ & $\mathbf{n}$ & $\%$ & $\mathbf{n}$ & $\%$ \\
\hline \multicolumn{11}{|l|}{ Gênero } \\
\hline Masculino & 2.584 & $75,87 \%$ & 5.123 & $73,60 \%$ & 6.186 & $74,43 \%$ & 5.961 & $74,22 \%$ & 5.056 & $73,11 \%$ \\
\hline Feminino & 822 & $24,13 \%$ & 1.838 & $26,40 \%$ & 2.125 & $25,57 \%$ & 2.070 & $25,78 \%$ & 1.860 & $26,89 \%$ \\
\hline Não especificado & 0 & $0,00 \%$ & 0 & $0,00 \%$ & 0 & $0,00 \%$ & 0 & $0,00 \%$ & 0 & $0,00 \%$ \\
\hline $\begin{array}{l}\text { Total de acidentes por } \\
\text { sexo }\end{array}$ & 3.406 & $100 \%$ & 6.961 & $100 \%$ & 8.311 & $100 \%$ & 8.031 & $100 \%$ & 6.916 & $100 \%$ \\
\hline \multicolumn{11}{|l|}{ Idade } \\
\hline 14 a 17 anos & 105 & $3,08 \%$ & 226 & $3,25 \%$ & 297 & $3,57 \%$ & 206 & $2,58 \%$ & 237 & $3,43 \%$ \\
\hline 18 a 21 anos & 551 & $16,18 \%$ & 1.107 & $15,90 \%$ & 1.402 & $16,87 \%$ & 1.326 & $16,62 \%$ & 1.151 & $16,64 \%$ \\
\hline 22 a 39 anos & 1.863 & $54,70 \%$ & 3.865 & $55,52 \%$ & 4.496 & $54,10 \%$ & 4.370 & $54,76 \%$ & 3.695 & $53,43 \%$ \\
\hline 40 a 59 anos & 831 & $24,40 \%$ & 1.620 & $23,27 \%$ & 1.951 & $23,47 \%$ & 1.918 & $24,04 \%$ & 1.687 & $24,39 \%$ \\
\hline acima de 60 anos & 56 & $1,64 \%$ & 143 & $2,05 \%$ & 165 & $1,99 \%$ & 160 & $2,01 \%$ & 146 & $2,11 \%$ \\
\hline $\begin{array}{l}\text { Total de acidentes por } \\
\text { faixa etária }\end{array}$ & 3.406 & $100 \%$ & 6.961 & $100 \%$ & 8.311 & $100 \%$ & 8.031 & $100 \%$ & 6.916 & $100 \%$ \\
\hline
\end{tabular}

Fonte: Souza-Filho EB, et al., 2020. Dados extraídos do CEREST de Franca, São Paulo. 


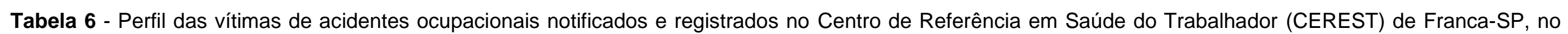
período de 2014 a 2018, conforme as variáveis Gênero $(\mathrm{N}=63.163)$ e Idade $(\mathrm{N}=63.112)$.

\begin{tabular}{|c|c|c|c|c|c|c|c|c|c|c|c|c|}
\hline \multirow[b]{2}{*}{ Variável } & \multicolumn{2}{|c|}{2014} & \multicolumn{2}{|c|}{2015} & \multicolumn{2}{|c|}{2016} & \multicolumn{2}{|c|}{2017} & \multicolumn{2}{|c|}{2018} & \multicolumn{2}{|c|}{$\begin{array}{c}\text { Total } \\
2009 \text { a } 2018\end{array}$} \\
\hline & $\mathbf{n}$ & $\%$ & $\mathbf{n}$ & $\%$ & $\mathbf{n}$ & $\%$ & $\mathbf{n}$ & $\%$ & $\mathbf{n}$ & $\%$ & $\mathbf{n}$ & $\%$ \\
\hline \multicolumn{13}{|l|}{ Gênero } \\
\hline Masculino & 4.478 & $71,53 \%$ & 3.813 & $71,44 \%$ & 3.804 & $70,34 \%$ & 4.263 & $68,36 \%$ & 4.368 & $69,37 \%$ & 45.636 & $72,25 \%$ \\
\hline Feminino & 1.782 & $28,47 \%$ & 1.524 & $28,56 \%$ & 1.604 & $29,66 \%$ & 1.973 & $31,64 \%$ & 1.910 & $30,33 \%$ & 17.508 & $27,72 \%$ \\
\hline Não especificado & 0 & $0,00 \%$ & 0 & $0,00 \%$ & 0 & $0,00 \%$ & 0 & $0,00 \%$ & 19 & $0,30 \%$ & 19 & $0,03 \%$ \\
\hline $\begin{array}{l}\text { Total de acidentes } \\
\text { por sexo }\end{array}$ & 6.260 & $100 \%$ & 5.337 & $100 \%$ & 5.408 & $100 \%$ & 6.236 & $100 \%$ & 6.297 & $100 \%$ & 63.163 & $100 \%$ \\
\hline \multicolumn{13}{|l|}{ Idade } \\
\hline 14 a 17 anos & 191 & $3,05 \%$ & 113 & $2,12 \%$ & 85 & $1,57 \%$ & 73 & $1,17 \%$ & 113 & $1,79 \%$ & 1.646 & $2,61 \%$ \\
\hline 18 a 21 anos & 997 & $15,93 \%$ & 769 & $14,41 \%$ & 715 & $13,22 \%$ & 815 & $13,07 \%$ & 763 & $12,12 \%$ & 9.596 & $15,20 \%$ \\
\hline 22 a 39 anos & 3.425 & $54,71 \%$ & 2.928 & $54,86 \%$ & 3.043 & $56,27 \%$ & 3.491 & $55,98 \%$ & 3.452 & $54,82 \%$ & 34.628 & $54,87 \%$ \\
\hline 40 a 59 anos & 1.495 & $23,88 \%$ & 1.400 & $26,23 \%$ & 1.413 & $26,13 \%$ & 1.662 & $26,65 \%$ & 1.769 & $28,09 \%$ & 15.746 & $24,95 \%$ \\
\hline acima de 60 anos & 152 & $2,43 \%$ & 127 & $2,38 \%$ & 152 & $2,81 \%$ & 195 & $3,13 \%$ & 200 & $3,18 \%$ & 1.496 & $2,37 \%$ \\
\hline $\begin{array}{l}\text { Total de acidentes } \\
\text { por faixa etária }\end{array}$ & 6.260 & $100 \%$ & 5.337 & $100 \%$ & 5.408 & $100 \%$ & 6.236 & 100 & 6.297 & $100 \%$ & 63.112 & $100 \%$ \\
\hline
\end{tabular}

Fonte: Souza-Filho EB, et al., 2020. Dados extraídos do CEREST de Franca, São Paulo. 


\section{Faixa Etária}

A faixa etária em que há predominância dos acidentes de trabalho se situa entre 22 e 39 anos, com 54,87\% $(n=34.628)$ dos casos. Valores semelhantes foram encontrados por Machado TAS (2007), com $52,4 \%$ dos acidentes ocorridos nesta mesma faixa etária. Em segundo lugar, encontra-se a faixa entre 40 e 59 anos $(24,95 \%, n=15.746)$ e em terceiro as idades de 18 a 21 anos $(15,20 \%, n=9.596)$, mantendo esta ordem durante os anos de 2009 a 2018 (Tabelas 5 e 6). Alguns fatores explicam este fato, dentre os quais pode-se citar que este é o intervalo de idade em que é mais comum a presença de indivíduo inserido no mercado de trabalho (ALMEIDA FSS, 2011). Esta proporção é encontrada também em nível nacional, demonstrando o perfil das vítimas para o qual as ações preventivas devem ser prioritariamente voltadas: homens, entre $22 \mathrm{e}$ 59 anos.

\section{CONCLUSÃO}

O presente estudo reforça a necessidade de medidas preventivas, especialmente no setor de serviços e indústria calçadista no caso da região analisada. Números tidos como não informados ou inconclusivos nas tabelas não permitem uma análise completamente fidedigna dos dados e evidenciam a urgência em averiguar os fatores que levam ao preenchimento incompleto das RAATs. A caracterização aqui exposta, ao interpretar e analisar os dados de uma década, pode colaborar para estes fins, sendo, portanto, de suma importância para embasar medidas de segurança de trabalho e, por fim, monitorar a saúde ocupacional da região, de forma a desonerar o SUS e o sistema previdenciário.

\section{REFERÊNCIAS}

1. ALMEIDA FSS. Epidemiologia descritiva dos acidentes de trabalho e das doenças relacionadas ao trabalho no Brasil, 1998 a 2008. Dissertação (Mestrado) - Faculdade de Ciências Médicas da Santa Casa de São Paulo, São Paulo, 2011.

2. ALMEIDA PCA, BARBOSA-BRANCO A. Acidentes de trabalho no Brasil: prevalência, duração e despesa previdenciária dos auxílios-doença. Revista Brasileira de Saúde Ocupacional, 2011; 36(124): 195-207.

3. BARBOSA RI, et al. Perfil dos pacientes com lesões traumáticas do membro superior atendidos pela fisioterapia em hospital do nível terciário. Acta Fisiátrica. 2013; 20(1): 14-19.

4. BASTOS PLM. Estudo dos acidentes de trabalho no setor da construção civil em Portugal. Dissertação (mestrado) Universidade Fernando Pessoa, Faculdade de Ciência e Tecnologia, Porto, 2017.

5. BRASIL. Casa Civil, Decreto n 3.048, de 6 de maio de 1999. Aprova o Regulamento da Previdência Social, e dá outras providências. Brasília, 1999.

6. BRASIL. Casa Civil, Resolução no 8.213, de 24 de julho de 1991, Da finalidade e dos princípios básicos da previdência social, Brasília, 1991.

7. BRASIL. Casa Civil. Lei no 6.367 , de 19 de outubro de 1976, art 2 ‥ Dispõe sobre o seguro de acidentes do trabalho a cargo do INPS e dá outras providências. Brasília, 1976.

8. BRASIL. Ministério da Saúde, Resolução oㅜ 510, Brasília, 7 de abril de 2016.

9. BRASIL. Secretaria Geral, Medida Provisória № 905, de 11 de novembro de 2019. Institui o Contrato de Trabalho Verde e Amarelo, altera a legislação trabalhista, e dá outras providências. Brasília, 2019.

10. BRASIL. Secretaria Geral, Medida Provisória № 955, de 20 de abril de 2020. Revoga a Medida Provisória ํo 905, de 11 de novembro de 2019, que institui o Contrato de Trabalho Verde e Amarelo e altera a legislação trabalhista. Brasília, 2020.

11. CORDEIRO R, et al. Subnotificação de acidentes do trabalho não fatais em Botucatu, SP, 2002. Revista de Saúde Pública, 2005; 39(2): 254-260.

12. FRANCO-BENATTI DM. Acidentes e doenças relacionadas ao trabalho na indústria de calçados de Franca-SP. Dissertação (mestrado) - Faculdade de Medicina de Ribeirão Preto da Universidade de São Paulo, Ribeirão Preto, $2011,87$.

13. IBGE. Censo Demográfico 2010. Instituto Brasileiro de Geografia e Estatística. Rio de Janeiro, 2011.

14. IBGE. Produto Interno Bruto dos Municípios 2017. Instituto Brasileiro de Geografia e Estatística. Disponível em: < https://cidades.ibge.gov.br/brasil/sp/franca/pesquisa/38/46996?ano=2017>. Acesso em: 12 de abril de 2020.

15. MACHADO TAS. Implantação e análise de sistema de captação de acidentes do trabalho no Hospital Escola da Faculdade de Medicina de Botucatu Dissertação (Mestrado em Saúde Pública) - Faculdade de Medicina de Botucatu, Universidade Estadual Paulista, Botucatu, 2007; 113. 
16. MINISTÉRIO DA ECONOMIA. Secretaria de Previdência. Dados estatísticos - saúde e segurança do trabalhador. Disponível em: <http://www.previdencia.gov.br/dados-abertos/dados-abertos-sst/>. Acesso em: 11 de abril de 2020.

17. MINISTÉRIO DA FAZENDA. Anuário Estatístico de Acidentes do Trabalho 2017 (AEAT). Brasília, 2017.

18. MINISTÉRIO DA SAÚDE. Notificações de acidentes do trabalho - fatais, graves e com crianças e adolescentes. Brasília, 2006.

19. MINISTÉRIO DO TRABALHO. Portaria no 3214/1978. Aprova as Normas Regulamentadoras - NR - do Capítulo V, Título II, da Consolidação das Leis do Trabalho, relativas à Segurança e Medicina do Trabalho. Brasília, 08 de junho de 1978.

20. PINTO JM. Tendência na incidência de acidentes e doenças de trabalho no Brasil: aplicação do filtro Hodrick-Prescott. Revista Brasileira de Saúde Ocupacional, 2017; 42(0).

21. SOUZA TV. A influência do sexo e do gênero nas questões envolvendo segurança e saúde do trabalhador. Revista Espaço Acadêmico, 2016, no 177. 